\title{
A Rare Case Report of Pyogenic Granuloma of Tongue
}

\author{
Vinson Louis Gonzaga Fernandes, Nina Margarida De Gouveia Pinto, Vibhav B. Sanzgiri, \\ Purva Khandolkar, Isha Rajendra Sukhthankar
}

Department of Otorhinolaryngology and Head \& Neck Surgery, Goa Medical College, Goa, India

Email: fernandesvinson@yahoo.com

How to cite this paper: Fernandes, V.L.G., Pinto, N.M. De G., Sanzgiri, V.B., Khandolkar, P. and Sukhthankar, I.R. (2018) A Rare Case Report of Pyogenic Granuloma of Tongue. International Journal of Otolaryngology and Head \& Neck Surgery, 7, 75-79.

https://doi.org/10.4236/ijohns.2018.73010

Received: March 14, 2018

Accepted: May 7, 2018

Published: May 10, 2018

Copyright (c) 2018 by authors and Scientific Research Publishing Inc. This work is licensed under the Creative Commons Attribution International License (CC BY 4.0). http://creativecommons.org/licenses/by/4.0/

\begin{abstract}
Pyogenic granuloma is an inflammatory hyperplasia secondary to chronic irritation. We report a case of a 24 -year-old male patient who presented with a pyogenic granuloma on the right lateral border of the tongue. We shall discuss the differential diagnosis and the treatment for the same.
\end{abstract}

\section{Keywords}

Pyogenic Granuloma, Tongue, Lateral Border

\section{Introduction}

Pyogenic granuloma is a relatively common, tumor-like, exuberant tissue response to localized irritation, trauma or hormonal factors [1]. Histologically it does not resemble a granuloma and never contains purulent material; hence calling it pyogenic granuloma is a misnomer. It usually occurs on the gingiva but uncommonly it can occur on extra gingival sites such as lips, tongue and buccal mucosa [2].

Owing to trauma from adjacent teeth or dentures, lateral side of the tongue is a common location [3]. It presents usually in the second decade of life. The objective of this case report is to acquaint surgeons around the world with the unusual presentation of pyogenic granuloma of tongue.

\section{Case Report}

A 24-year-old male from Vasco, Goa, cook by occupation, presented to the outpatient department with history of noticing a mass on the right side of his tongue since 3 months. It was insidious in onset and gradually progressive, having the size of a small pea which progressed to the size of small lime and was associated with pain on and off. He was a non-smoker and was able to eat and drink 
comfortably. Past history was unremarkable. There were no constitutional symptoms such as loss of appetite or weight loss.

Physical examination revealed no abnormalities or cervical lymphadenopathy. Intra orally he had a 2 by $2 \mathrm{cms}$ whitish red pedunculated mass with an irregular margin and smooth surface on the right lateral border of the tongue at the junction of the anterior $2 / 3^{\text {rd }}$ and posterior $1 / 3^{\text {rd }}$ (Figure 1 ). It was firm, mobile and non-tender and did not bleed on touch.

Rest of the oral cavity and oropharynx was found to be within normal limits.

A differential diagnosis of hemangioma or pyogenic granuloma was made. Routine laboratory investigations were done. Treatment was given in the form of an excisional biopsy under local anaesthesia and sent for histopathology examination. The defect was closed primarily with 3 - 0 vicryl sutures.

Patient recovered well postoperatively.

The histopathological report came consistent with pyogenic granuloma. The sections revealed granulation tissue with dense chronic inflammatory infiltrate lined by stratified squamous epithelium showing hyperplasia (Figure 2).

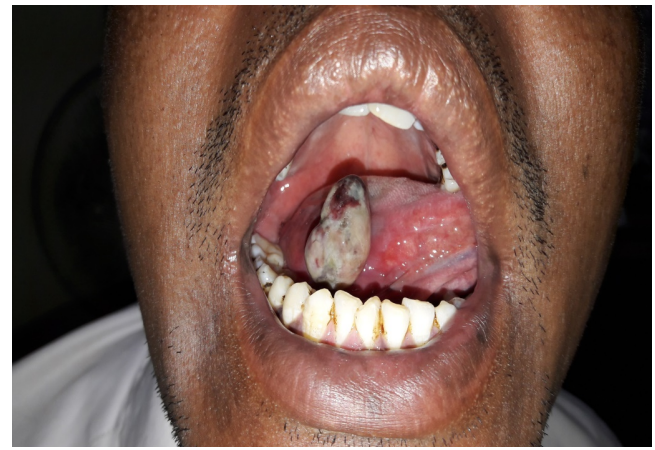

Citation: Original source.

Figure 1. Clinical photograph showing pyogenic granuloma on right lateral border of tongue.

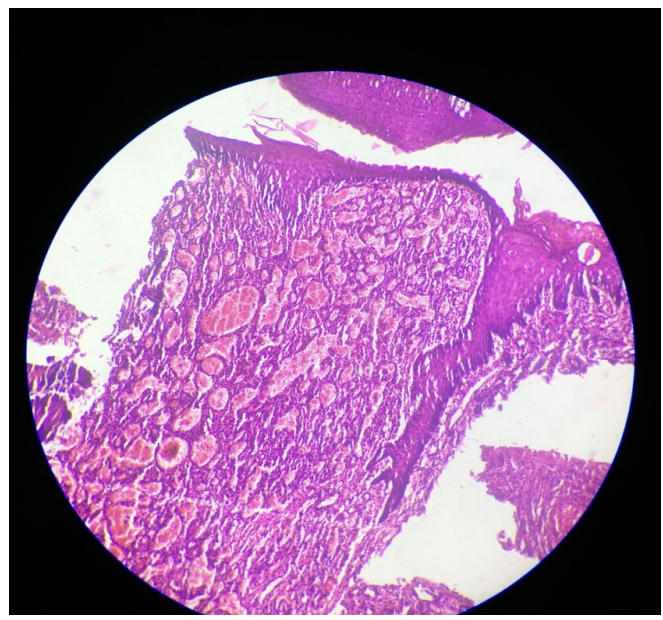

Citation: Original source.

Figure 2. Photomicrograph showing capillary proliferation with overlying squamous epithelium and infiltration by inflammatory cells ( $\mathrm{H} \& \mathrm{E}, 40 \times)$. 
Our patient was followed up monthly for over 6 months and had no recurrence. Overall prognosis was good.

Patients consent was taken for publishing this case report.

\section{Discussion}

Pyogenic granulomas can be found on the gingiva (60\%), lip (14\%), tongue (9\%) and the buccal mucosa (7\%) [4]. Although it may occur in all ages, it is predominant in the second decade of life in young adult females, possibly because of the vascular effects of female hormones [2]. It has now been accepted that the lesion is an exaggerated localized connective tissue reaction to minor injury or irritation [5].

Affected most commonly are Individuals with poor oral hygiene and chronic irritants in the oral cavity (e.g. orthodontic treatment, braces, salivary gland stones).

Clinically it is a small, deep red to purple lesion which can be sessile or pedunculated. The surface may be smooth, lobulated, ulcerated and can bleed spontaneously or upon slight trauma. Sizes range from 0.5 to $3 \mathrm{cms}$ and may suddenly grow over weeks or months to subsequently remain indefinitely [6].

Even though a clinical diagnosis of pyogenic granuloma can be very accurate, radiological and histopathological investigations aid in confirming the diagnosis and providing adequate treatment. X-rays are used to identify a foreign body and to rule out malignancy. Definitive diagnosis of pyogenic granuloma can be made only after histopathological examination of the biopsied tissue. Majority of the lesion is formed by a lobulated mass of angiomatous tissue with sparse collagen, which is infiltrated by lymphocytes, plasma cells and neutrophils [7].

Polymerase chain reaction investigations for human papilloma virus and human herpes virus type have yielded negative results [8].

In 2010, a case of pyogenic granuloma was reported around an implant. This will be a more common occurrence as the number of implants and associated peri-implantitis cases increase [9] [10].

Differential diagnosis for pyogenic granuloma are kaposi's sarcoma, angiosarcoma, non-hodgkin's lymphoma, metastatic tumor, post extraction granuloma, pregnancy tumor, peripheral giant cell granuloma, peripheral ossifying fibroma, hemangioma, peripheral fibroma, leiomyoma, hemangioendothelioma, hemangiopericytoma, bacillary angiomatosis [11].

Treatment of pyogenic granuloma involves the removal of the causative agent which may sometimes result in spontaneous resolution. Adequate excision of the lesion is the treatment of choice [12].

Other surgical modalities that can be used are cryosurgery, lasers, injection of ethanol or corticosteroid and sodium tetradecyl sulphate sclerotherapy. $2 \mathrm{~A}$ newly developed tool, ultrasonic scissors can be safely utilized to excise this lesion on the tongue, reducing the blood loss and operative time substantially [13]. 


\section{Conclusion}

Pyogenic granuloma of tongue can result from poor oral hygiene, especially an uncleaned tongue and a traumatic bite to the tongue while eating. The clinical features of pyogenic granulomas that are very characteristic, help in making a differential diagnosis but are inadequate for a definitive diagnosis. They require a thorough histopathological diagnosis to differentiate them from true tumors of the oral cavity.

\section{References}

[1] Sills, E.S., Zegarelli, D.J., Hoschander, M.M. and Strider, W.E. (1996) Clinical Diagnosis and Management of Hormonally Responsive Oral Pregnancy Tumor. The Journal of Reproductive Medicine, 41, 467-470.

[2] Jafarzadeh, H., Sanatkhani, M and Mohtasham, N. (2006) Oral Pyogenic Granuloma: A Review. Journal of Oral Science, 48, 167-175.

https://doi.org/10.2334/josnusd.48.167

[3] Croton, E. and Kale, U. (2003) Midline Pyogenic Granuloma of Tongue: Two Case Studies. European Archives of Otorhinolaryngology, 260, 840-847. https://doi.org/10.1007/s00405-003-0629-4

[4] Angelopoulus, A.P. (1971) Pyogenic Granuloma of the Oral Cavity: Statistical Analysis of Its Clinical Features. Journal of Oral Surgery, 29, 840-847.

[5] Shenoy, S.S. and Dinkar, A.D. (2006) Pyogenic Granuloma Associated with Bone Loss in an Eight Year Old Child: A Case Report. Journal of Indian Society of Pedodontics and Preventive Dentistry, 24, 201-203.

https://doi.org/10.4103/0970-4388.28078

[6] Patil, K., Mahima, V.G. and Lahari, K. (2006) Extragingival Pyogenic Granuloma. Indian Journal of Dental Research, 17, 199-202. https://doi.org/10.4103/0970-9290.29864

[7] Bhaskar, S.N. and Jacoway, J.R. (1966) Pyogenic Granuloma-Clinical Features, Incidence, Histology and Result of Treatment. Report of 142 Cases. Journal of Oral Surgery, 24, 391-398.

[8] Sato, H., Takeda, Y. and Satoh, M. (2002) Expression of Endothelial Receptor Tyrosine Kinase Tie2 in Lobular Capillary Hemangioma of Oral Mucosa: An Immunohistochemical Study. Journal of Oral Pathology and Medicine, 31, 432-438. https://doi.org/10.1034/j.1600-0714.2002.310708.x

[9] Olmedo, D.G., Paparella, M.L., Brandizzi, D. and Cabrini, R.L. (2010) Reactive Lesions of Peri-Implant Mucosa Associated with Titanium Dental Implants: A Report of 2 Cases. International Journal of Oral and Maxillofacial Surgery, 39, 503-507. https://doi.org/10.1016/j.ijom.2009.11.007

[10] Acharya, P.N., Gill, D. and Lloyd, T. (2011) Pyogenic Granuloma: A Rare Side Complication from an Orthodontic Appliance. Journal of Orthodontics, 38, 290-293. https://doi.org/10.1179/14653121141569

[11] Amirchaghmaghi, M., Farnaz, F., Nooshin, M. and Mozafari, P.M. (2008) Extragingival Pyogenic Granuloma: A Case Report. Cases Journal, 1, 371.

https://doi.org/10.1186/1757-1626-1-371

[12] Lawoyin, J.O., Arotiba, J.T. and Dosumu, O.O. (1997) Oral Pyogenic Granuloma. A Review of 38 Cases from Ibadan, Nigeria. British Journal of Oral and Maxillofacial 
Surgery, 35, 185-189. https://doi.org/10.1016/S0266-4356(97)90561-1

[13] Momamd, I., Periasamy, C. and Dawood, Y. (2011) Tongue Pyogenic Granuloma Excision Using Ultrasonic Scissors. Archives of Orofacial Sciences, 6, 43-45. 